\title{
THE COMPARISON OF ANALOGOUS REACTIONS OF MACROMOLECULES WITH LOW-MOLECULAR MODELS
}

\author{
Rolf C. SCHUlz \\ Institute of Macromolecular Chemistry, Technische Hochschule Darmstadt, \\ West Germany
}

\begin{abstract}
Most experiments for the chemical transformation of polymers start from the assumption that the reactivity of a functional group in a macromolecule has to be the same as one in a low molecular compound. But it turns out that usually the reaction on the polymer is faster or slower than the reaction of the model compound, or the reaction with the polymer proceeds in a different way and the reaction products differ from those of the model compound. These phenomena are called 'polymeric effects'. It depends on the property to be compared as to which model reflects the polymer in the best way. These general considerations are exemplified by three reactions.

(a) The optical and chiroptical properties of polymers with atropisomeric groups in the pendant sidegroups and in the backbone are the same as for three low-molecular model compounds. But the racemization rates of the polymers are much slower than those of the models.

(b) Electron-donor-acceptor complexes between polyesters with fluorene rings and TCNQ or TCNE were prepared and compared with the corresponding models. The value of the equilibrium constant $(K)$ is only reached by models with at least two donor groups per molecule. In the oligomer range, the constant $K$ depends upon the degree of polymerization. The presence of neighbouring donor groups seems to be the cause of the greater stability of the polymer complex.

(c) Preparation and properties of $N$-chlorinated nylon 66 is described. The i.r. spectra are the same as those of the model compounds but the reactivity of the chlorine is usually different. $N$-chloro-nylon oxidizes secondary alcohols faster and often to a higher yield than the models. Primary alcohols are transformed to the esters. The advantages of a polymeric oxidation reagent are discussed.

At higher temperature or upon irradiation, a rearrangement takes place and the chlorine moves from the $\mathrm{N}$-atom to a $\mathrm{C}$-atom in the model as well as in the $\mathrm{N}$-chloro-nylon. This reaction can be followed by i.r. spectra or by the decrease in oxidation ability.
\end{abstract}

\section{GENERAL CONSIDERATIONS}

Chemical reactions with synthetic or biological polymers play a very important role in technology as well as in science and medicine. For more than fifty years they have therefore been the subject of a great deal of research 
and there is an enormous amount of patents and publications on them ${ }^{1}$. The aims and methods of these investigations differ widely. Usually the macromolecules are chemically changed either to modify their properties or to analyse the primary and secondary structure. Sometimes the polymer is used as a support, matrix or template for other reactions ${ }^{2}$, i.e. the polymer becomes part of a cycle of reactions but returns to its original chemical state after the reactions. Furthermore there are many experiments, in which macromolecular substances with specific functional groups behave as catalysts $^{3}$, inhibitors, photosensitizers ${ }^{4}$ etc. It should be mentioned that some of these experiments can help to elucidate the mechanism of enzyme reactions.

In all these experiments we have to start from the assumption that the reactivity of a functional group in a macromolecule has to be the same as one in a low-molecular compound. But we often learn that this assumption is not right, i.e. the reaction on the polymer turns out to be different from an analogous reaction with a low-molecular model compound. As this differing behaviour is a consequence of the polymeric structure of the reaction partner this phenomenon is called 'polymeric effects'. We talk of polymeric effects if the reaction of the polymer is faster or slower than the reaction of the model compound, or if the reaction with the polymer proceeds by a different route and the reaction products differ from those of the model compound. Sometimes the polymeric effects depend on the molecular weight of the polymers.

There are different reasons for polymeric effects, for instance the inaccessibility of the functional groups, secondary structure, influence of neighbouring groups, charge distribution, solvation etc. It depends on the nature of the macromolecule and the type of reaction as to which influence predominates and whether there are polymeric effects. Often a definite explanation for polymeric effects has been impossible up to now. Certainly it is very important which model compounds for the polymers are chosen for a comparison and which characteristics are examined. For instance, we can compare physical (u.v., i.r., n.m.r.) or chemical properties (dissociation constants, rate constants, yields etc.) reaction mechanisms or stereochemistry. But sometimes it is difficult to find a low-molecular compound which is comparable with the polymer and could therefore serve as a model. It should be emphasized that model compounds mostly imitate only one property. That is why we should have to use various model compounds if we want to compare several characteristics of the polymer. If we, however, compare a model compound with several features of the polymer we often find a correspondence with only a few qualities: we see great differences, however, as far as other qualities are concerned. So we find here, too, that every comparison would be defective.

In order to compare the chemical reactivity of a polymer one usually takes a model compound which corresponds with a base unit of the macromolecule. If, however, we want to study chemical or physical interactions of adjacent functional groups it is necessary that the model compounds shall have at least the structure of dimers or trimers. But for stereochemical comparisons or as models of secondary structures we generally need linear or cyclic oligomers.

Many examples in the literature demonstrate these general considerations and conclusions. I prefer, however, to cite our own research comparisons 
between model compounds and polymer reactions. I shall discuss the rate constants of an isomerization reaction, the equilibrium constants of EDAcomplexes and the chemical reactivity of $\mathrm{N}$-chlorocarboxamides.

\section{THE RACEMIZATION OF POLYMERS WITH ATROPISOMERIC DIPHENYL GROUPS ${ }^{5}$}

(Together with R. H. JUNG)

There are some organic compounds which are chiral because of hindered rotation around a $\mathrm{C}-\mathrm{C}$ single bond and can therefore be separated into antipodes ${ }^{6}$. These stereo isomers are called 'atropisomers'. Some of them are very stable; in other cases the enantiomers racemize when heated up. This reaction proceeds by first-order kinetics and can be clearly observed in the change of optical activity. The following equation applies:

$$
-\mathrm{d} c / \mathrm{d} t=-\mathrm{d} \alpha / \mathrm{d} t=k_{\text {rac }} \times \alpha
$$

and therefore:

$$
-\ln \alpha_{0} / \alpha_{t}=k_{\text {rac }} \times t
$$

The rate of the racemization depends on the chemical structure, and the substituents as well as the solvents.

In our experiments on optically active polymers we also produced some which contain atropisomeric diphenyl derivatives either as pendant groups or in their backbone ${ }^{5}$. We examined the absorption spectra, the circular dichroism and the racemization of these polymers ${ }^{7,8}$. We then compared these properties with those of the corresponding model compounds. The preparation of a polymer with pendant atropisomeric groups is shown in Scheme 1 (equation 3). 2-Methyl-6-nitrobiphenyl-2'-carboxylic acid (I) was separated with the aid of quinine (according to Bell ${ }^{9}$ into the antipodes, and the dextrorotatory form $\left([\alpha]_{D}=+67.6\right.$ in dioxane) was transferred into the acid chloride (II) $\left([\alpha]_{\mathrm{D}}=+183\right)$.

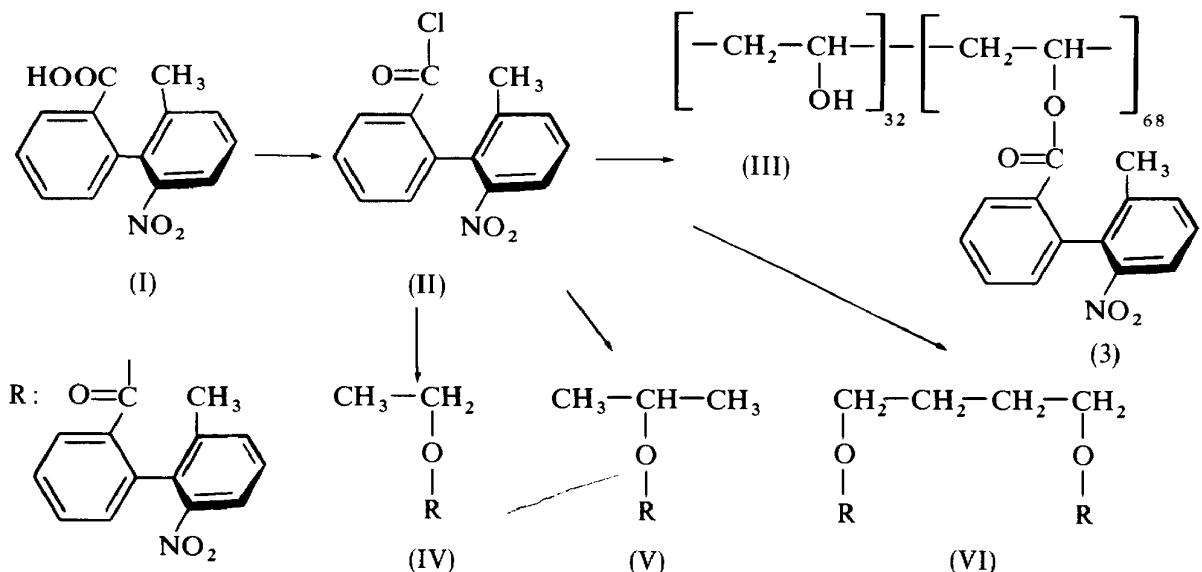

Scheme 1 
By the reaction of II with polyvinyl alcohol we obtained the polymer III. The esters of 2-methyl-6-nitrobiphenyl-2'-carboxylic acid with ethanol (IV), isopropanol (V) and butanediol (VI) ${ }^{10}$ were prepared as low-molecular model compounds (see Scheme 1). The absorption spectra of these compounds have no characteristic maxima, but are very similar to one another. The molar rotations of the model compounds and the polymer are shown in Table 1 .

Table 1. Molar rotation [M]* of the polyvinylester of 2-methyl-6-nitrobiphenyl-2'carboxylic acid (III) and the model compounds (IV). (V) and (VI).

\begin{tabular}{rrrrrrcc}
\hline$\lambda(\mathrm{nm})$ & 589 & 578 & 546 & 436 & 405 & $A_{0} \times 10^{-7}$ & $\lambda_{0}(\mathrm{~nm})$ \\
\hline III & 139.7 & 149.6 & 185.0 & 644.5 & 1346 & 0.85 & $385 \pm 5$ \\
IV & 144.1 & 154.9 & 192.0 & 671.3 & 1406 & 0.95 & $385 \pm 5$ \\
V & 112.5 & 120.6 & 149.7 & 509.4 & 1062 & 0.77 & $382 \pm 5$ \\
VI & 347.4 & 372.4 & 462.8 & 1631.8 & 3485 & 1.2 & $285 \pm .5$ \\
\hline
\end{tabular}

* In dioxane at $22^{\circ} \mathrm{C}$; concentration $c=1 \mathrm{~g} / 100 \mathrm{ml}$ : for III calculated on base units.

Between 589 and $436 \mathrm{~m} \mu$ a single-term Drude equation is valid. The constants determined by Yang-Doty plots can be found in the last column of Table 1 .

$$
[\alpha]=A_{0} /\left(\lambda^{2}-\lambda_{0}^{2}\right)
$$

The similarities between the polymers and the model compounds are particularly significant in the ORD- and CD-curves (Figure 1, Figure 2 and Table 2).

With regard to these properties the different low-molecular model compounds coincide very well with the polymer. Experiments on the kinetics of the racemization, however, lead to a completely different result. If we plot the relative change of the rotation on a logarithmic scale as a function of time we get straight lines for all the compounds examined here. This means that the polymers as well as the model compounds racemize according to a first-order reaction. The rate constant $k_{\mathrm{rac}}$ and the half-life time for the model compounds are the same within the limit of the error; in contrast to this racemization of the polymer takes place with only half the rate (Figure 3 and Table 3). A chain degradation or a split-off of sidegroups did not take place during the thermal treatment which was tested by viscosity and $\mathrm{N}$ analyses. A possible influence of the viscosity of the polymer solution could also be excluded by comparative experiments ${ }^{11}$. We therefore conclude that this low rate of racemization is to be explained by the fact that the whole coiled macromolecule and the adjacent substituents cause an additional hindrance to internal rotation around the biphenyl single bond.

This polymeric effect should become even more evident if the rotationhindered biphenyl bond does not belong to the sidegroup but is part of the main chain. We therefore prepared some polyamides, polyurethanes and model compounds based on (+)-2,2'-diaminobinaphthyl-(1,1') (VII) $2,2^{\prime}, 3,3^{\prime}$-tetramethylbenzidin (VIII) and 2,2-'dimethoxydiphenic acid (IX) ${ }^{10}$ (equations 5,6 and 7).

The dextro-rotatory form of IX was obtained with 70 per cent optical purity and the laevo-rotatory with 98 per cent optical' purity. For the racemization experiments we only used the polyamide $(\mathrm{X})$ and the corresponding 
THE COMPARISON OF ANALOGOUS REACTIONS OF MACROMOLECULES<smiles>CC(C)(C)Nc1ccc2ccccc2c1-c1c(NC(=O)c2ccc(C(=O)I)cc2)ccc2ccccc12</smiles>

(VII)<smiles>Cc1c(N)ccc(-c2ccc(N)c(C)c2C)c1C</smiles><smiles>[CH]1C=CC=C1</smiles><smiles>[R]C(=O)Nc1ccc(-c2ccc(NC)c(C)c2C)c(C)c1C</smiles>

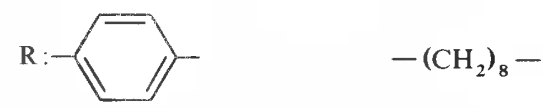

(VIIIa)

(VIIIb)
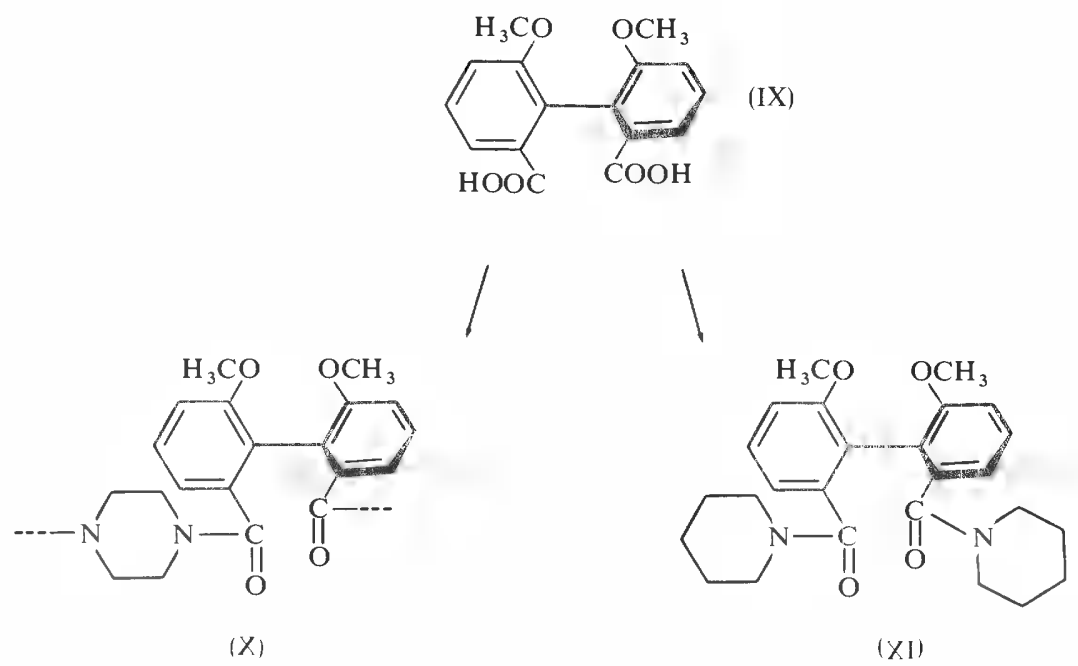


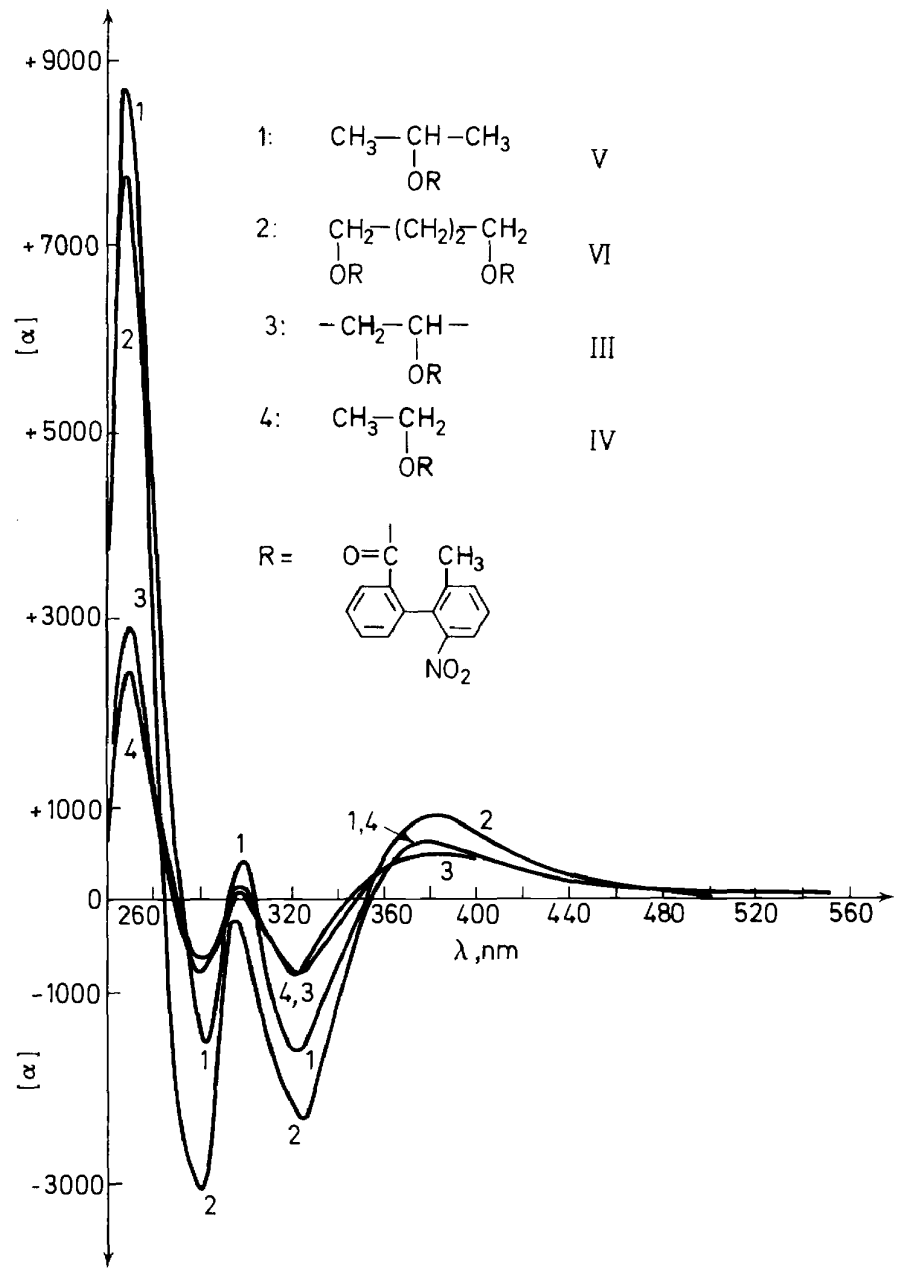

Figure 1. ORD of esters of 2-methyl-6-nitrobiphenyl-2'-carboxylic acid with polyvinylalcohol (III) and low molecular model compounds (in dioxane). 


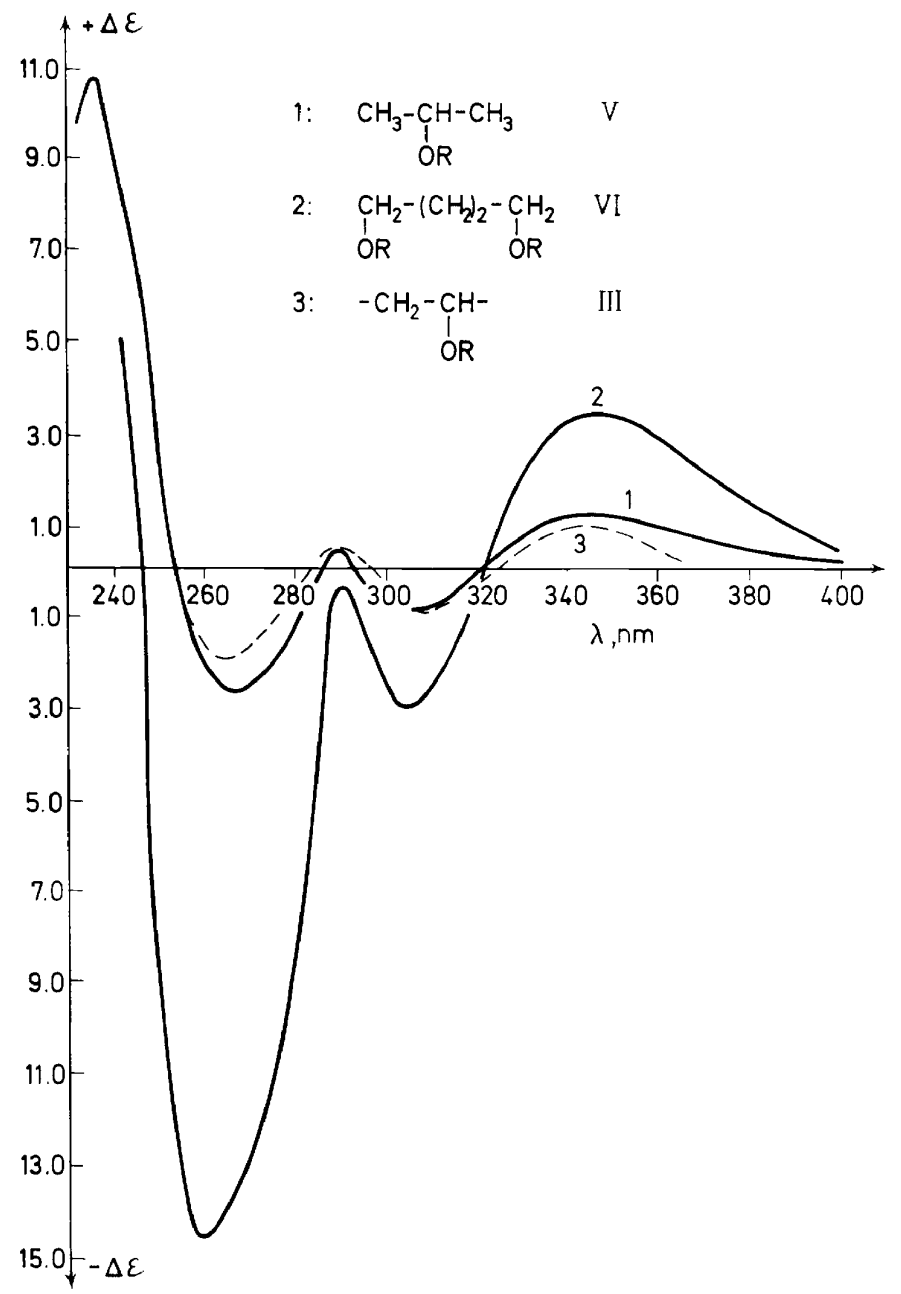

Figure 2. $\mathrm{CD}$ of esters of 2-methyl-6-nitro-biphenyl-2'-carboxylic acid with polyvinylalcohol (III) and low molecular model compounds (in dioxane). 


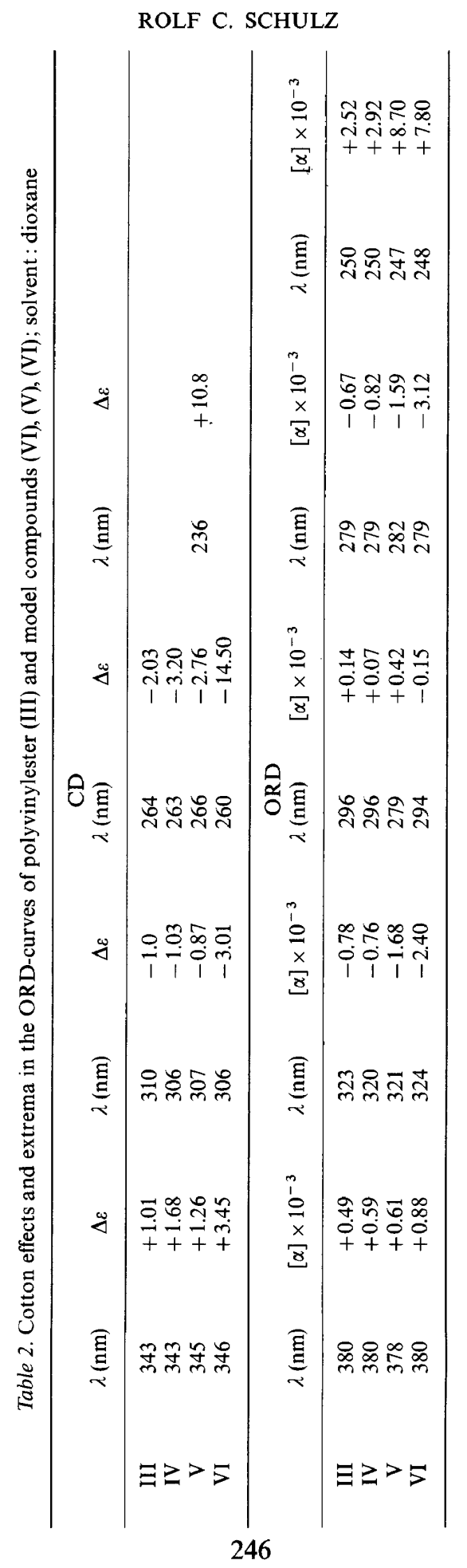




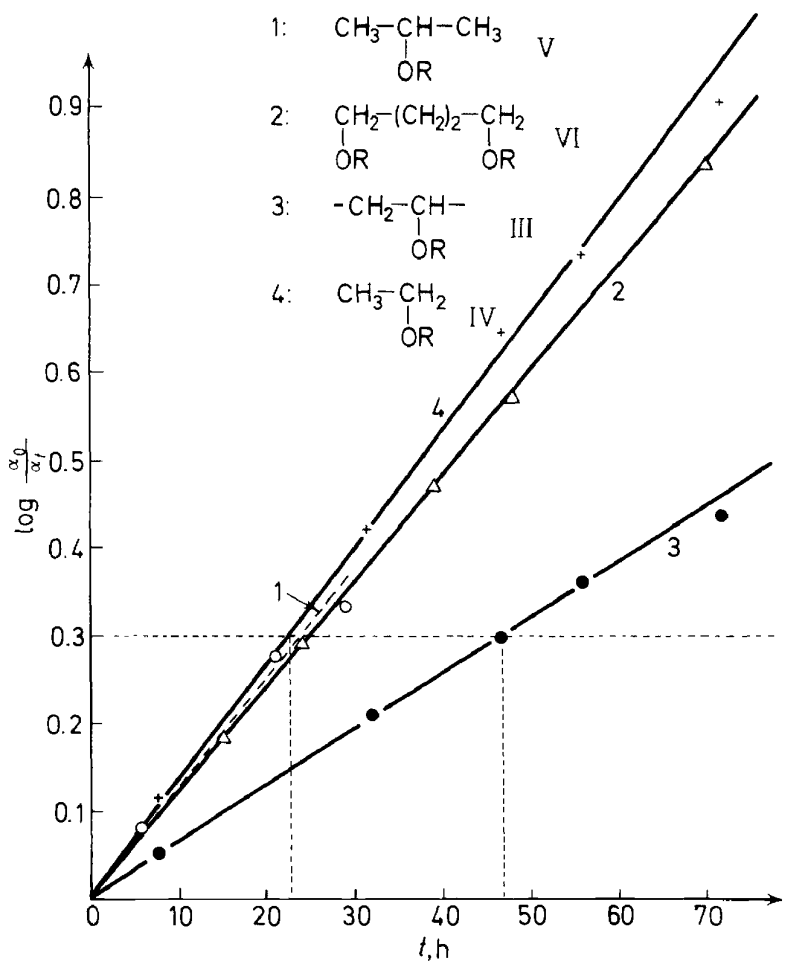

Figure 3. First-order plots of racemization of a polymer with atropisomeric biphenyl groups (III) and corresponding model compounds.

Table 3. Racemization of polyvinylester of 2-methyl-6-nitrobiphenyl-2'-carboxylic acid (III) and the model compounds (IV), (V) and (VI); temp.: $120^{\circ} \mathrm{C}$; solvent : dioxane; $\mathbf{R}:-\mathrm{C}=\mathrm{O} \quad \mathrm{CH}_{3}$ concentration: $0,1 \%$

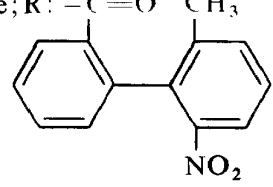<smiles>[R20]CC([R2])C(C)O[R]</smiles>

(III)
(IV)<smiles>[R]CCCC[R]</smiles>

(VI)

\begin{tabular}{lrrrr}
\hline$k_{\text {rac }} \times 10^{6}$ & & & \\
$\left(\mathrm{sec}^{-1}\right)$ & 4.0 & 8.3 & 7.9 & 7.7 \\
$\tau_{\frac{1}{2}}(\mathrm{~h})$ & 48.1 & 23.2 & 24.5 & 25.0 \\
\hline
\end{tabular}




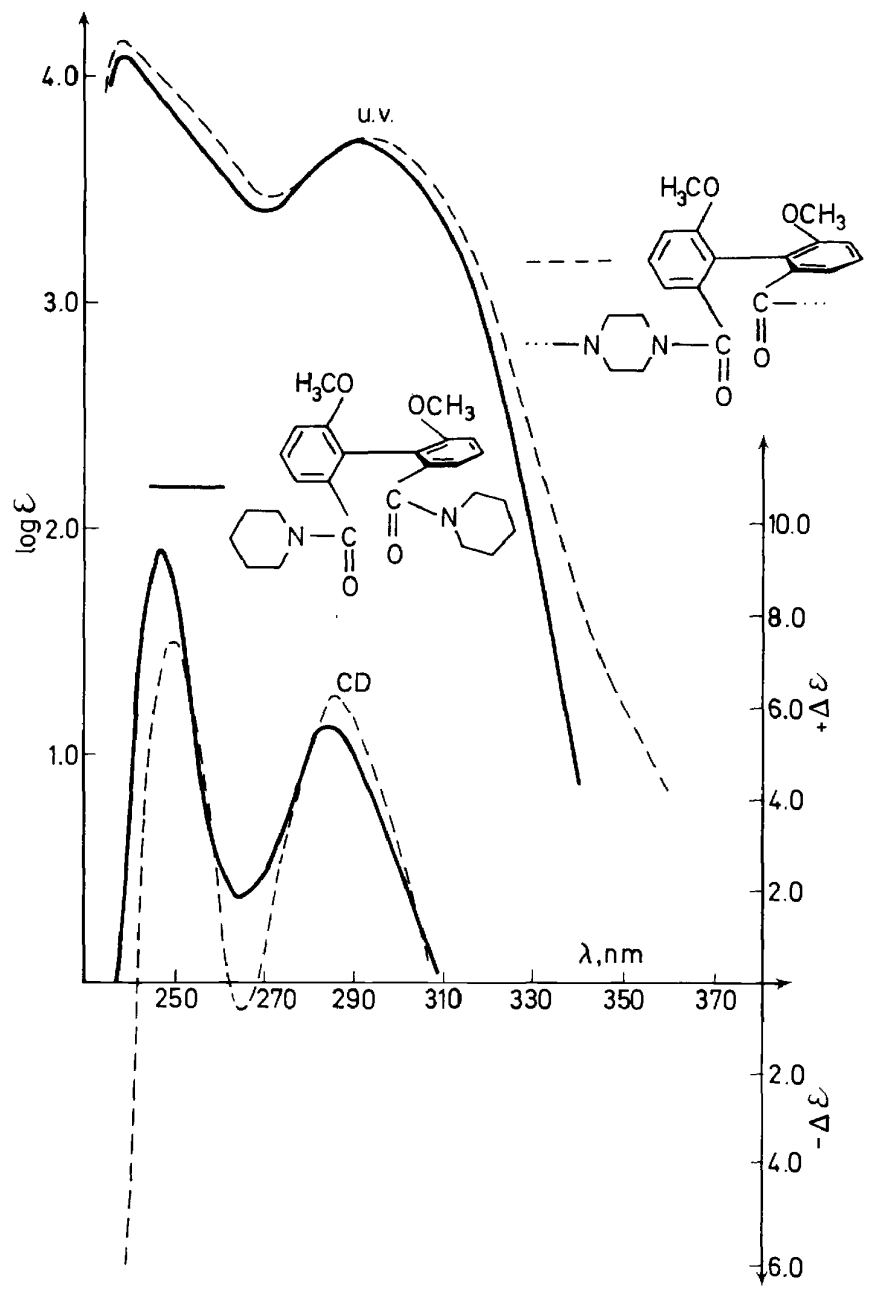

Figure 4. Some u.v.- and CD-spectra of a polyamide based on 2,2'-dimethoxy-diphenic acid (X) (- - $)$ and a corresponding model compound (XI) (- $(-)$.

Table 4. Specific rotation $[\alpha]$ of dextro-rotatory and laevo-rotatory polyamide (X) and model compound (XI)*. Solvent: DMF; temp. $21^{\circ} \mathrm{C}$.

\begin{tabular}{lccccc}
\hline & $\begin{array}{c}\text { Concentration } \\
\mathrm{g} / 100 \mathrm{ml}\end{array}$ & 578 & 546 & 436 & 405 \\
\hline$(+) \mathrm{X}$ & 0.527 & +62.4 & +73.1 & +162.5 & +223.0 \\
$(+) \mathrm{XI}$ & 0.284 & +58.1 & +68.7 & +142.6 & +193.7 \\
\hline$(-) \mathrm{X}$ & 0.5 & -95.9 & -114.2 & -250.0 & -342.9 \\
$(-) \mathrm{XI}$ & 0.5 & -73.1 & -86.0 & -183.2 & -246.3 \\
\hline
\end{tabular}

* The optical purity of the dimethoxydiphenic acid (IX) was $\sim 70$ per cent for $(+)$ (IX) and 98 per cent for $(-)$ (IX). 
Table 5. Cotton effects and extrema in the ORD curves of polyamide (X) and model compound (XI)*. Solvent : chloroform

\begin{tabular}{|c|c|c|c|c|}
\hline & \multicolumn{4}{|c|}{$C D$} \\
\hline & $\lambda(\mathrm{nm})$ & $\Delta \varepsilon$ & $\lambda(\mathrm{nm})$ & $\Delta \varepsilon$ \\
\hline \multirow{4}{*}{$\begin{array}{l}(+) X \\
(+) X I\end{array}$} & 286 & +6.32 & 250 & +7.57 \\
\hline & 284 & +5.74 & 247 & +9.55 \\
\hline & \multicolumn{4}{|c|}{ ORD } \\
\hline & $\lambda(\mathrm{nm})$ & {$[\mathbf{M}]$} & $\lambda(\mathrm{nm})$ & {$[\mathbf{M}]$} \\
\hline$(+) X$ & 298 & +12250 & 273 & -16600 \\
\hline$(+) X I$ & 298 & +11900 & 273 & -7200 \\
\hline
\end{tabular}

* Optical purity $\sim 70$ per cent; [M] and $\Delta \varepsilon$ calculated on the basis of molecular weight $M=352.38$.

model compound (XI) derived from the dextrorotatory form of the dimethyldiphenic acid because the polymers VIIIa, $b$ were not soluble enough and the polymers of VII were not available in sufficient quantities. Again we notice that the polymer X and the model compound XI correspond in their u.v. spectra and their chiroptical properties (see Tables 4 and 5, and Figure 4). These properties arise from the interaction of electrons in the chromophore groups and are therefore not influenced by the molecular weight. But the shape of the molecules and the flexibility of the groups depend to a high degree on the size of the molecule. That is why we notice also in this case where the atropisomer groups are parts of a macromolecule a strong retardation of the racemization (see Table 6). The half-life time for the racemization

Table 6. Racemization of dextro-rotatory polyamide $(\mathrm{X})$ and the model compounds $(+)(\mathrm{XI})$ and $(-)(\mathrm{XI})$. Solvent: DMF; temp. $110^{\circ} \mathrm{C}$.

\begin{tabular}{lccc}
\hline & $(+) \mathrm{X}$ & $(+) \mathrm{XI}$ & $(-) \mathrm{XI}$ \\
\hline$k_{\mathrm{rac}} \times 10^{6}\left(\mathrm{sec}^{-1}\right)$ & 2.4 & 6.12 & 6.09 \\
$\tau_{\frac{1}{2}},(\mathrm{~h})$ & 81.6 & 31.4 & 31.6 \\
\hline
\end{tabular}

of the polymer at $110^{\circ} \mathrm{C}$ in DMF is almost three times as long as that for the model compound. We regard this case as a sterically caused polymeric effect. The next example shows the influence of the molecular weight on the equilibrium constant of EDA complexes.

\section{EDA COMPLEXES OF SOME OLIGOESTERS AND MODEL COMPOUNDS $^{12}$}

(Together with $\mathrm{H}$. TANAKa)

During recent years many authors have examined polymeric EDA complexes ${ }^{13}$. We have to distinguish four types of complexes (see Scheme 2). 
CT complexes with polymers

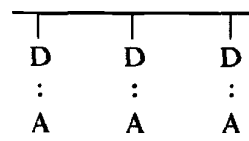

(a)

\begin{tabular}{ccc}
\hline & 1 & T \\
D & D & D \\
$:$ & $\vdots$ & $\vdots$ \\
A & A & A \\
$\perp$ & $\perp$ & L \\
\hline
\end{tabular}

(c)

\begin{tabular}{ccc}
\hline & & A \\
A & A & A \\
$:$ & $:$ & $:$ \\
D & D & D
\end{tabular}

(b)

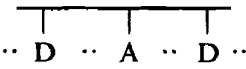

(d)

This means : in (a) a great number of donor groups $\mathrm{D}$ are linked to the macromolecular backbone and the acceptor A is a low-molecular compound. In (b), however, the acceptor groups A are linked to the macromolecule. Furthermore, it is possible [as in (c)] that both components of the EDA complex are attached to macromolecules ${ }^{14}$. Some experiments have been reported in which the polymer contains donor groups as well as acceptor groups (d) and therefore an intra-molecular complex-formation is possible ${ }^{15}$.

Most of the polymer-EDA-complexes which have been examined, however, belong to the first-named type, i.e. the donor groups are part of the macromolecules and become complexed with low-molecular acceptors. The equilibrium constant $K$ can be determined by the absorption spectra. Here the Benesi-Hildebrand-Scott equation is usually taken; it applies for lowmolecular EDA complexes ${ }^{16}$.

$$
\frac{C_{\mathrm{AO}} \times C_{\mathrm{DO}}}{D}=\frac{1}{K \times \varepsilon}+\frac{1}{\varepsilon} \times C_{\mathrm{DO}}
$$

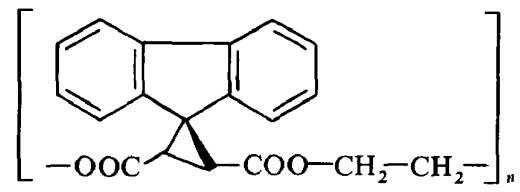

(XII)<smiles>COC(=O)C1C(=O)C12c1ccccc1-c1ccccc12</smiles><smiles>CC(=O)C1CC12c1ccccc1-c1ccccc12</smiles>

(XIV)<smiles>O=C(O)C1CC12c1ccccc1-c1ccccc12</smiles><smiles>COC(=O)C1CC12c1ccccc1-c1ccccc12</smiles>

(XV) 
In equation $8, C_{\mathrm{AO}}$ and $C_{\mathrm{DO}}$ are respectively the concentration of the acceptor and donor groups, $D$ is the optical density, $K$ is the equilibrium constant, and $\varepsilon$ is the molar coefficient of extinction.

In plotting $\left(C_{\mathrm{AO}} \times C_{\mathrm{DO}}\right) / D$ as a function of $C_{\mathrm{DO}}$ the constants $K$ and $\varepsilon$ are determined by graphical methods.

For our experiments we prepared a polyester (XII) from ethylene glycol and trans-2,3-dicarboxyspirocyclopropane-1,9'-fluorene; furthermore we

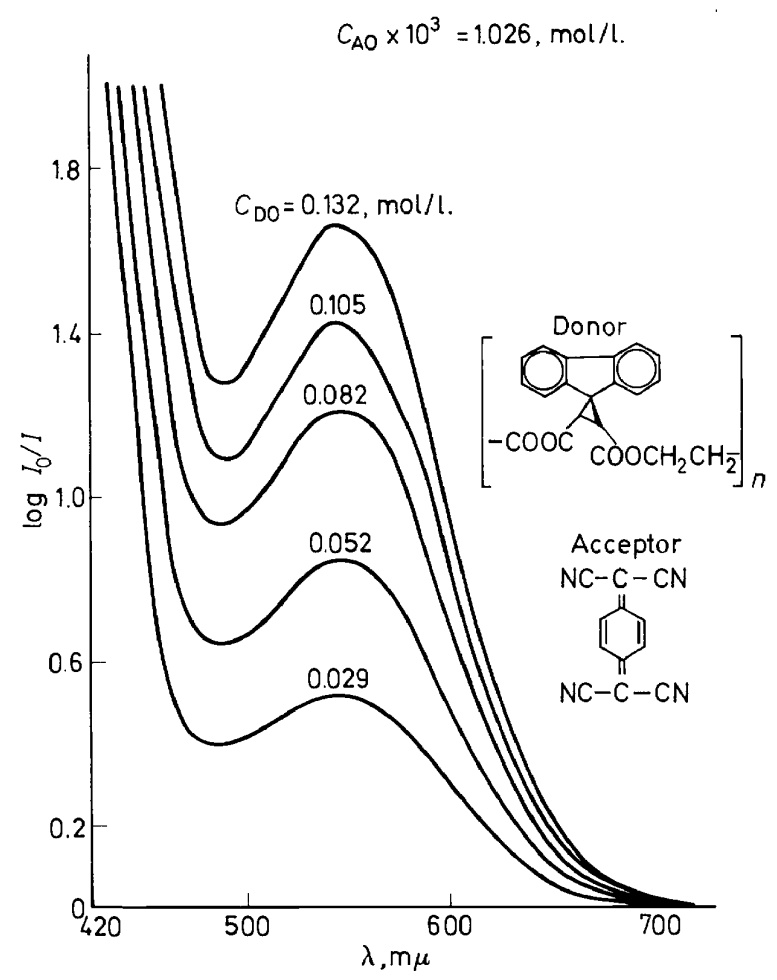

Figure 5. Absorption spectra of EDA complexes between TCNQ and a polyester of trans2,3-dicarboxyspirocyciopropane-1,9'-fluorene.

synthesized the model compounds (XIII) to (XV) which correspond respectively to one and two base units of the polymer ${ }^{12}$. The synthesis is shown in Scheme 3 . The fluorene-groups are $\pi$-donors which together with the acceptors tetracyanoquinodimethane(TCNQ) or tetracyanoethylene (TCNE) form EDA-complexes. In u.v. spectra we have two CT-bands. The following considerations, however, are restricted to TCNQ-complexes and the long wave CT-band. Experimental details and a detailed discussion have recently been published ${ }^{12}$. In Figure 5 the absorption spectra of the polymer donoracceptor complex with constant acceptor and variable donor concentration are shown. 


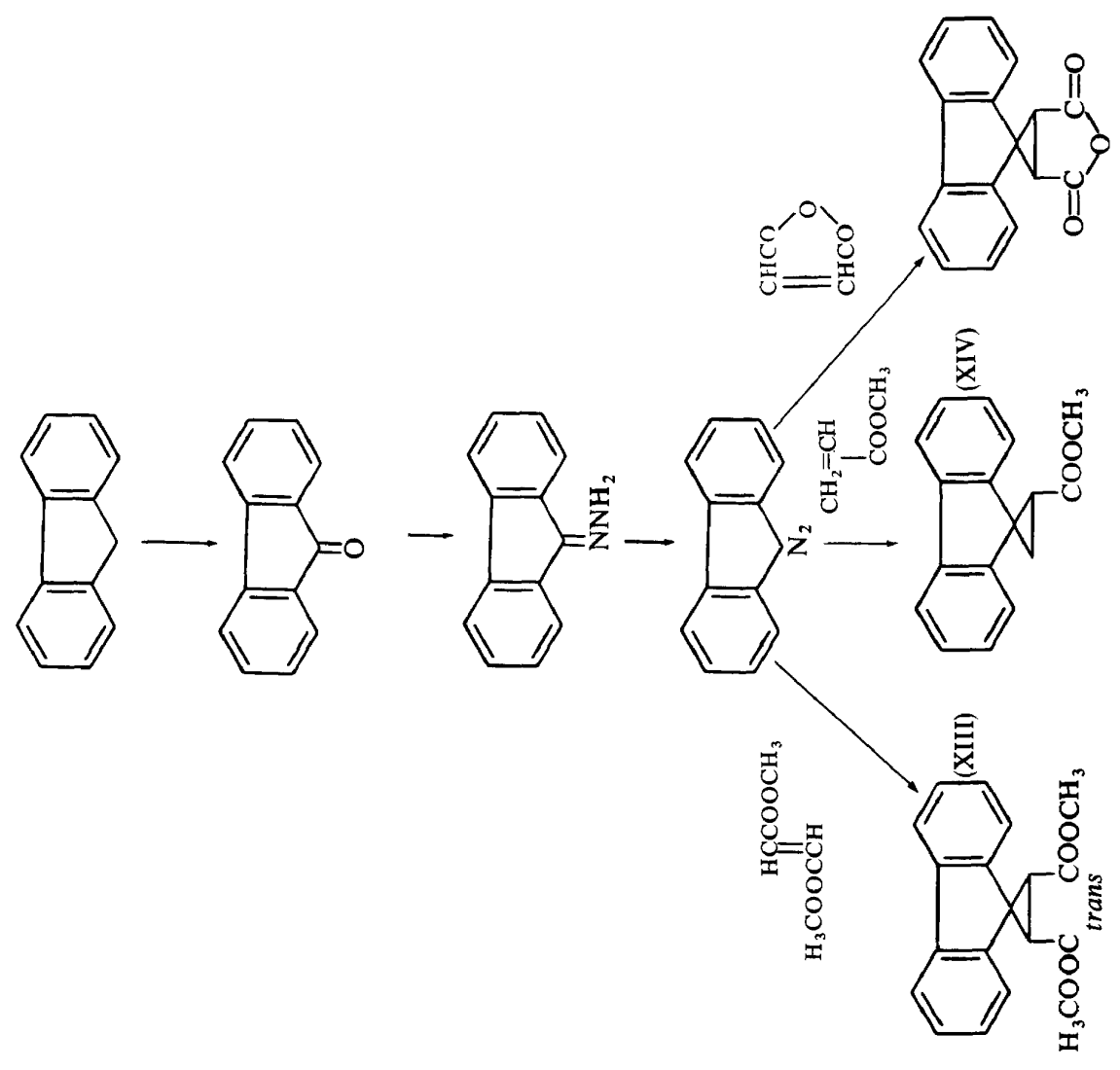



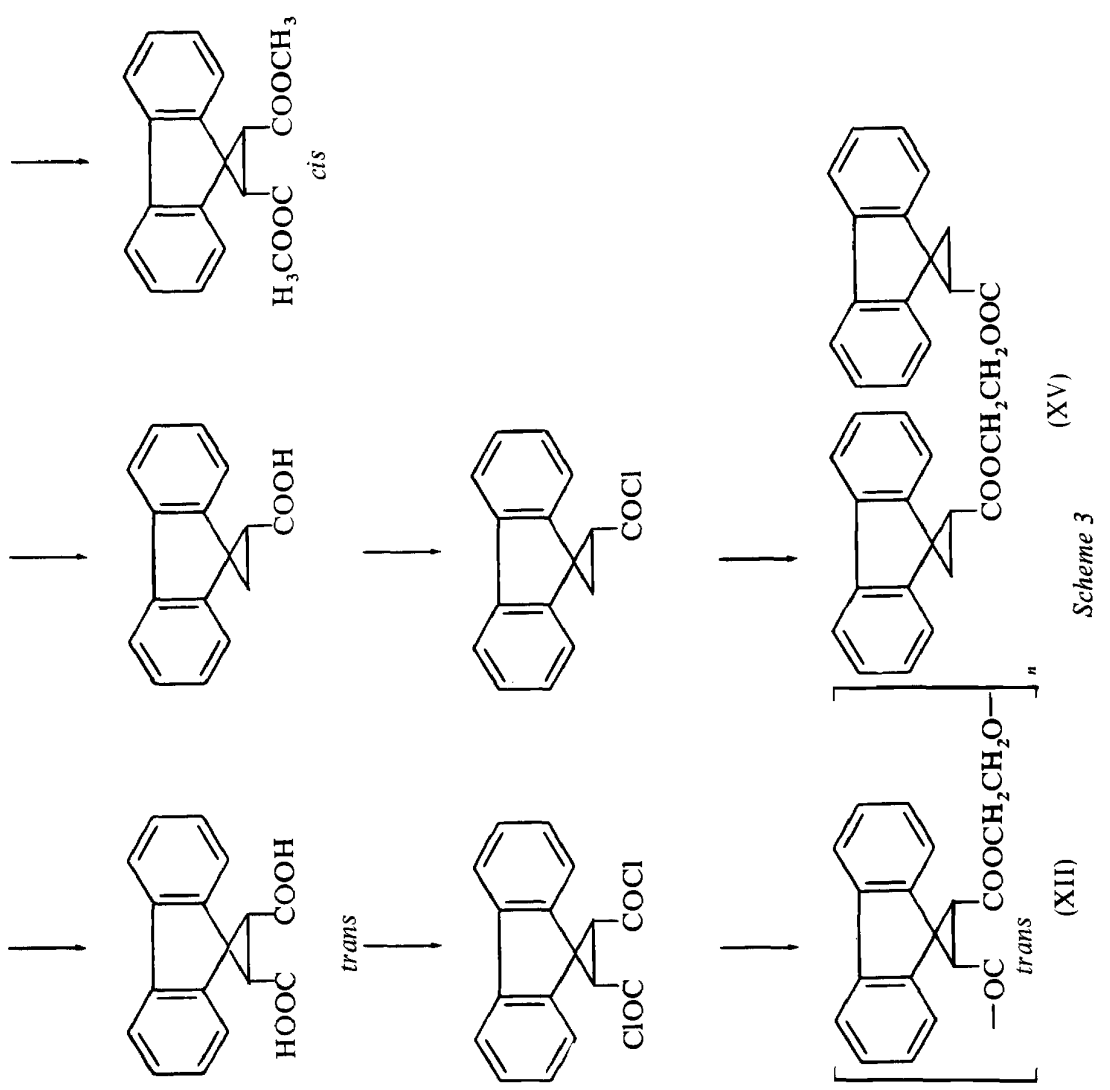
ROLF C. SCHULZ

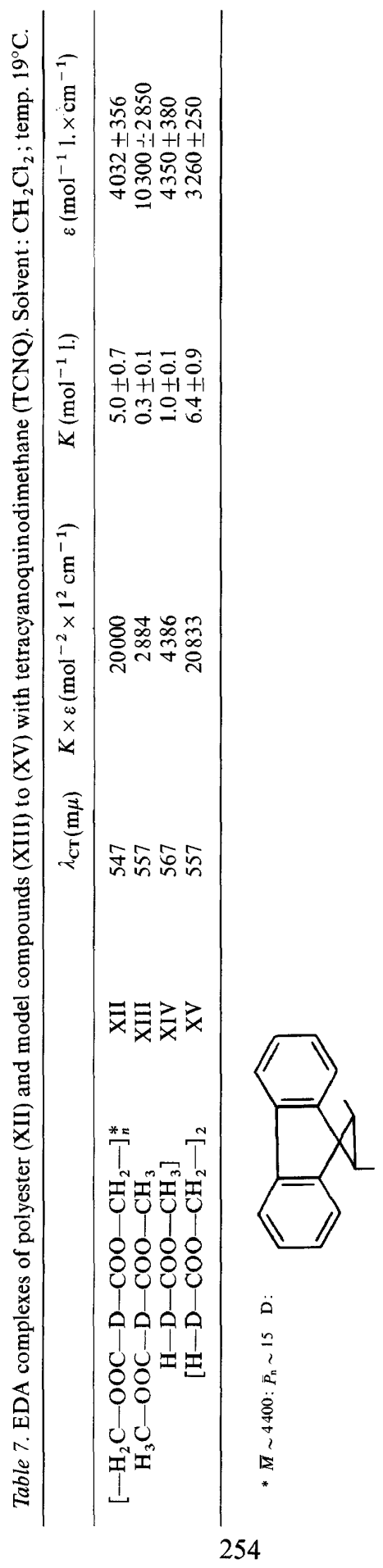


In all cases there is a great excess of donor groups, $\left(\mathrm{D}: \mathrm{A}=1: 0.78 \times 10^{-2}\right.$ to $1: 36 \times 10^{-2}$ ) that means $1 \mathrm{~mol}$ acceptor per 28 to $127 \mathrm{~mol}$ donor groups. But it can be shown that there is only one kind of complex whose composition is probably $1: 1$. The absorption maximum of the CT-bands is $547 \mathrm{~m} \mu$. Calculation according to Benesi-Hildebrand-Scott yields for the product $K \varepsilon=20000$ (see Table 7).

The dimethyl ester of the trans-dicarboxylic acid (XIII), whose structure corresponds almost exactly to one base unit of the polyester, forms an EDAcomplex with a CT-band at $557 \mathrm{~m} \mu$ under the same conditions; the product $K \varepsilon$, however, is only 2900 , that is $\sim 15 \%$ of that of the polyester. Neither does the complex formation of model compound XIV correspond to the polymer. But the compound $\mathrm{XV}$ which corresponds to two base units of the polyester, forms an EDA complex with a similar equilibrium constant to that of the polymer (see Table 7). We can be almost certain that in this case, too, we have a 1:1 complex, despite the excess of donor, i.e. only one fluorene ring of the dimer is complexed with the TCNQ-molecule. Although it has not been proved it seems obvious that here an acceptor-molecule is embedded sandwich-like between two donor-groups of the dimer.

In any case these experiments show that a simple model compound does not really reflect the properties of the polymer. The presence of neighbouring donor groups seems to be the cause of the greater stability of the polymer complex although the donor groups are not directly involved in the formation of the complex. This reaction can therefore only be imitated with models which also contain several donor groups.

Furthermore we prepared a homologous series of oligoesters of the cis-2,3,dicarboxyspirocyclopropane-1, $9^{\prime}$-fluorene (XVI) in order to determine the

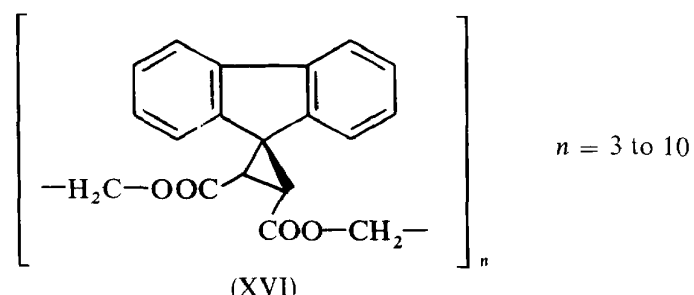

influence of the number of donor groups per molecule on complex formation ${ }^{17}$. Together with TCNQ or TCNE they form EDA complexes, whose absorption spectra were recorded with different acceptor/donor ratios. The CT-bands always lay between 548 and $550 \mathrm{~m} \mu$. In all cases the data could be described by the equation of Benesi-Hildebrand-Scott. It is surprising that the intercept decreases with increasing degree of polymerization, i.e. the product $K \times \varepsilon$ increases (see Figure 6 and Table 8). According to Liptay's method $^{18}$ we can show that here, too, we find only one type of complex; furthermore we may assume that the degree of polymerization has no influence on the ionization potential of the donor group (i.e. of the fluorene ring) and on the Coulomb interaction energy. The molar extinction coefficient should therefore be the same for all oligomer complexes. This means, how- 


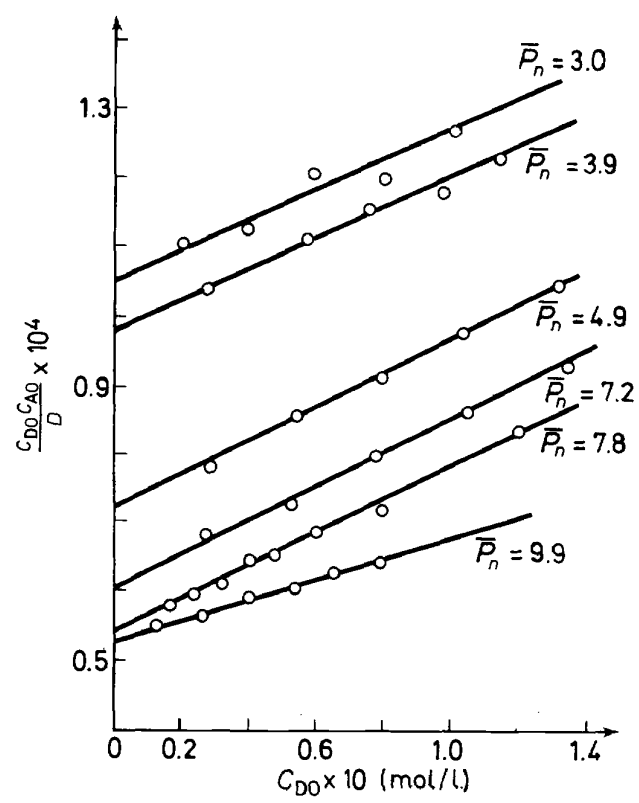

Figure 6. Benesi-Hildebrand-Scott plots of EDA-complexes between cis-oligoesters (XVI) and TCNQ.

ever, that the equilibrium constant increases with an increasing degree of polymerization, at least in this oligomer range.

By statistical calculations and the introduction of an 'effective donor concentration' it is possible to derive a modified Benesi-Hildebrand-Scott equation ${ }^{17}$. The degree of polymerization $\bar{P}_{n}$ is part of this equation as well as the quantity $\bar{m}$ which gives the number of all donor groups being involved in complex formation.

$$
\begin{gathered}
\frac{C_{\mathrm{DO}} \times C_{\mathrm{AO}}}{D}=\frac{\bar{P}_{n}}{\bar{K}^{\prime} \times \varepsilon^{\prime}\left[P_{n}-(\bar{m}-1)\right]}+\frac{1}{\varepsilon^{\prime}} C_{\mathrm{DO}} \\
K \times \varepsilon \times \bar{P}_{n}=K^{\prime} \varepsilon^{\prime}\left[\bar{P}_{n}-(\bar{m}-1)\right]
\end{gathered}
$$

According to these equations the plotting of $K \times \varepsilon \times \bar{P}_{n}$ against $\bar{P}_{n}$ should result in a straight line with the abscissal section $(\bar{m}-1)$ and the slope $K^{\prime} \times \varepsilon^{\prime}$. In fact the observed values for complex formation with TCNQ as well as with TCNE fit this equation very well (Figure 7). For the TCNQ complexes we find for the product $K^{\prime} \times \varepsilon^{\prime}=23200$; and for $\bar{m}$ we get a value of 2.8 ; this means that we have an EDA complex, in which on the average two or three donors are complexed with one acceptor. For the TCNE complexes we get $\bar{m}=2.4$. These values do not tell us anything about the geometrical arrangement and the spatial structure of the complex, but it is likely that the structure here is again sandwich-like, because of the close neighbourhood and the rather restricted mobility of the donor groups attached very tightly to the backbone. 
This assumption is supported by space-filling models and also explains the greater stability of the oligomer complexes compared with monomer complexes.

Although in the oligomers three donors per acceptor are involved in the complex because of these spatial arrangements, the electronic interaction

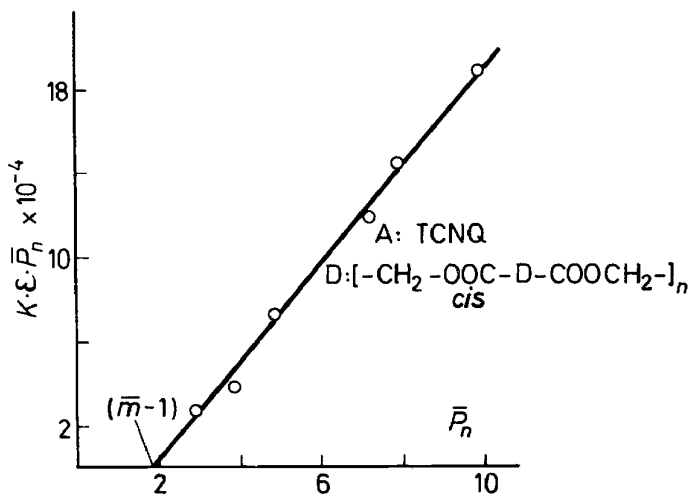

Figure 7. Plot according to equation 10 for EDA-complexes between cis-oligoesters (XVI) and TCNQ; values of Figure 6.

only takes place between one donor and one acceptor group (as may be concluded from the u.v. spectra).

Other authors ${ }^{19}$ too, assume that polymeric EDA-complexes may have sandwich-like structures; but they did not see any relationship between complex stability and degree of polymerization. Probably this effect becomes sufficiently evident only in the oligomer range.

These examples show how important it is even with apparently simple equilibrium reactions with polymers, to study low-molecular model compounds. In the following section some irreversible reactions between a highly reactive polymer and low-molecular substrates will be described.

Table 8. EDA complexes of oligomeric esters of cis-2,3dicarboxyspirocyclopropane-1,9'-fluorene (XVI) with tetracyanoquinodimethane (TCNQ). Solvent: $\mathrm{CH}_{2} \mathrm{Cl}_{2}$.

\begin{tabular}{ccc}
\hline $\bar{P}_{n}$ & $\lambda_{\mathrm{CT}}(\mathrm{m \mu})$ & $\begin{array}{c}K \times \varepsilon \\
\left(\mathrm{mol}^{-2} \times 1^{2} \times \mathrm{cm}^{-1}\right)\end{array}$ \\
\hline$\sim 3.0$ & & 9470 \\
$\sim 3.9$ & 550 & 10180 \\
$\sim 4.9$ & 550 & 14840 \\
$\sim 7.2$ & 550 & 16540 \\
$\sim 7.8$ & 550 & 18510 \\
$\sim 9.9$ & 546 & 19020 \\
\hline
\end{tabular}




\section{PREPARATION AND PROPERTIES OF $N$-CHLORO-POLYAMIDES ${ }^{20,21}$}

\section{(Together with H. SCHUTTENBERG, M. MüLLER and K. HAHN)}

Carboxamides or imides, in which an $\mathrm{H}$-atom is replaced by a halogen atom are extremely reactive compounds and are therefore often used in preparative organic chemistry. The best known compounds of this kind are $\mathrm{N}$-bromo-succinimide, $\mathrm{N}$-bromo-hydantoin, $\mathrm{N}$-bromo-acetamide etc. Although there are many polymers with amide groups or imide groups in the main chain or in pendant groups, polymer $N$-halogenamides have as yet only been described in two examples ${ }^{22}$. In continuation of earlier experiments $^{23}$ on polymers with reactive groups we prepared the $N$-chloro<smiles>CCCC(=O)N(C)I</smiles>

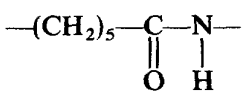<smiles>CNCCNC(=O)CCC(=O)I</smiles><smiles>CNCCN(Cc1ccc(C(C)=O)cc1)C(=O)c1ccccc1</smiles><smiles>CNCCNCCNCCCCOc1cccc(OC)c1</smiles><smiles>CCC(C)C(=O)NCc1ccccc1</smiles><smiles>CCC(c1ccccc1)C1C(=O)NC(=O)C1C</smiles>

derivatives of the seven following polyamides: nylon 3 , nylon 6, nylon 66, polyhexamethylene terephthalamide, polyhexamethylene- $m$-benzene-sulphonamide, polystyrene-co-maleimide and poly- $N$-benzylacrylamide. But the ensuing considerations are restricted to the $N$-chlorination of nylon 66 and to the reactions of $\mathrm{N}$-chloro-nylon (equation 11).

$$
\prod_{\mathrm{O}}^{\mathrm{C}-\left(\mathrm{CH}_{2}\right)_{4}-\mathrm{C}-\mathrm{NH}-\left(\mathrm{CH}_{2}\right)_{6}-\mathrm{NH}-\rightarrow} \text { (XVII) }
$$

(XVIII)

We used acetyl and propionyl derivatives of monamines and diamines (e.g. XIX to XXI), as model compounds. The chlorinations were done with $t$-butylhypochlorite (dissolved in tetrachloroethane) or chloromonoxide (dis- 


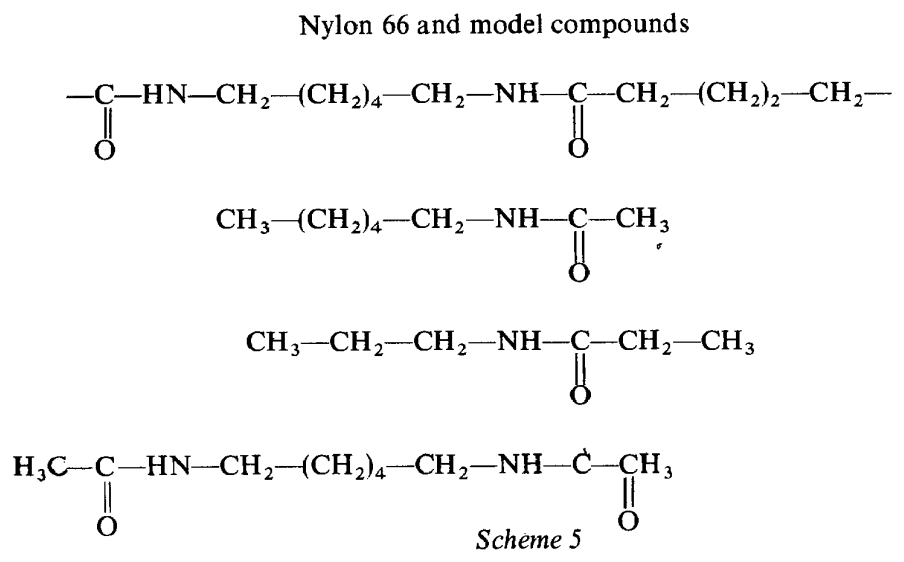

$(\mathrm{XXI})$

solved in tetrachloroethane); gaseous chlorine and aqueous solutions of potassium hypochlorite ${ }^{20}$ can also be used. Finely divided nylon 66 was suspended in $\mathrm{C}_{2} \mathrm{H}_{2} \mathrm{Cl}_{4}$ and the chlorination agent was added between $-20^{\circ} \mathrm{C}$ and $+15^{\circ} \mathrm{C}$. After 3 to 12 hours we got a clear solution which was dropped into ether. The resulting $N$-chloro-nylon (XVIII) is a white powder. As it does not contain any $\mathrm{NH}$-groups and therefore no $\mathrm{H}$-bonds can be formed, it is easily soluble in tetrachloroethane, chloroform and benzene in contrast to nylon 66 . In the i.r. spectrum the NH-bands are missing at 3300 and $3080 \mathrm{~cm}^{-1}$ and the amide bands II at $1530 \mathrm{~cm}^{-1}$; the carbonyl band is shifted by $35 \mathrm{~cm}^{-1}$ towards longer wavenumbers (Figure 8 ). In the model compound (XIX) and its $N$-chloroderivatives we find the same bands and band shifts (Figure 9). The n.m.r. spectra confirm the structure mentioned above.
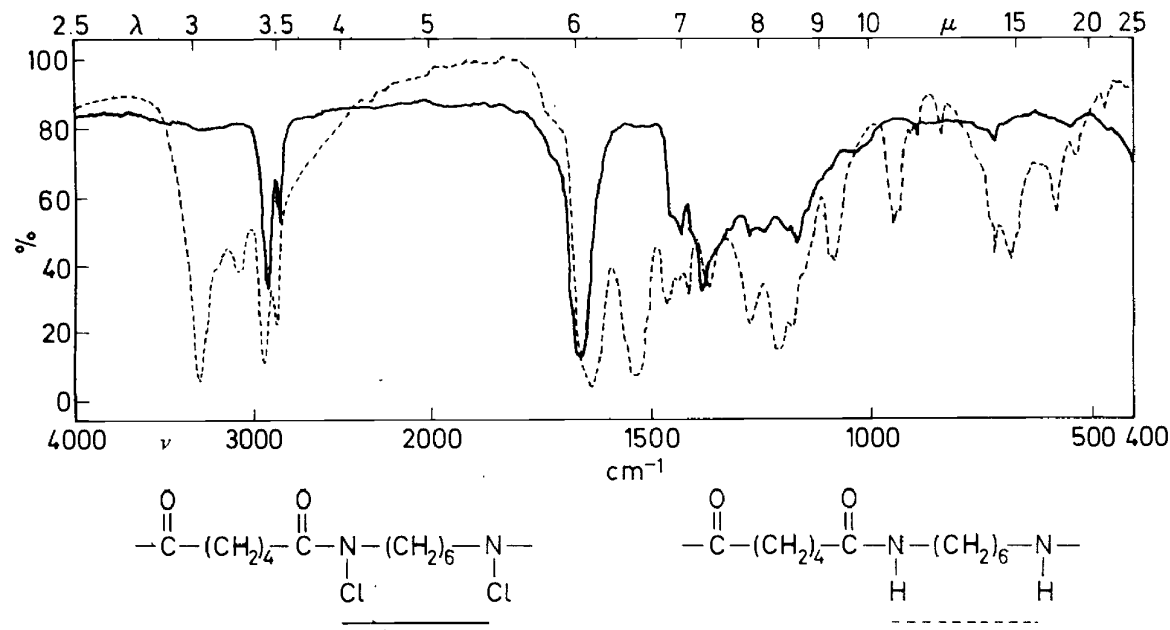

Figure 8. The i.r. spectra of nylon 66 (XVII) and chlorinated nylon 66 (XVIII). 
ROLF C. SCHULZ

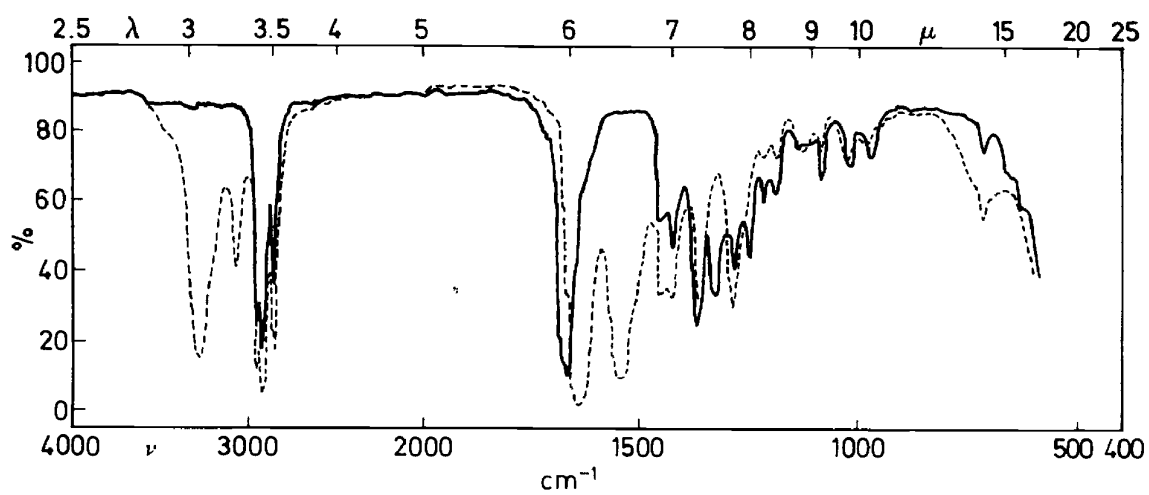

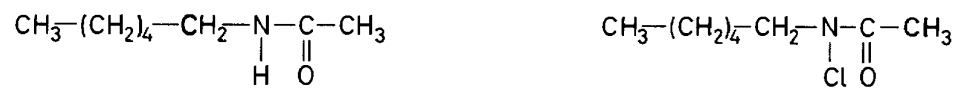

Figure 9. The i.r. spectra of $N$-acetyl-n-hexylamine (XIX) (- - ) and the $N$-chlorinated compounds (-).

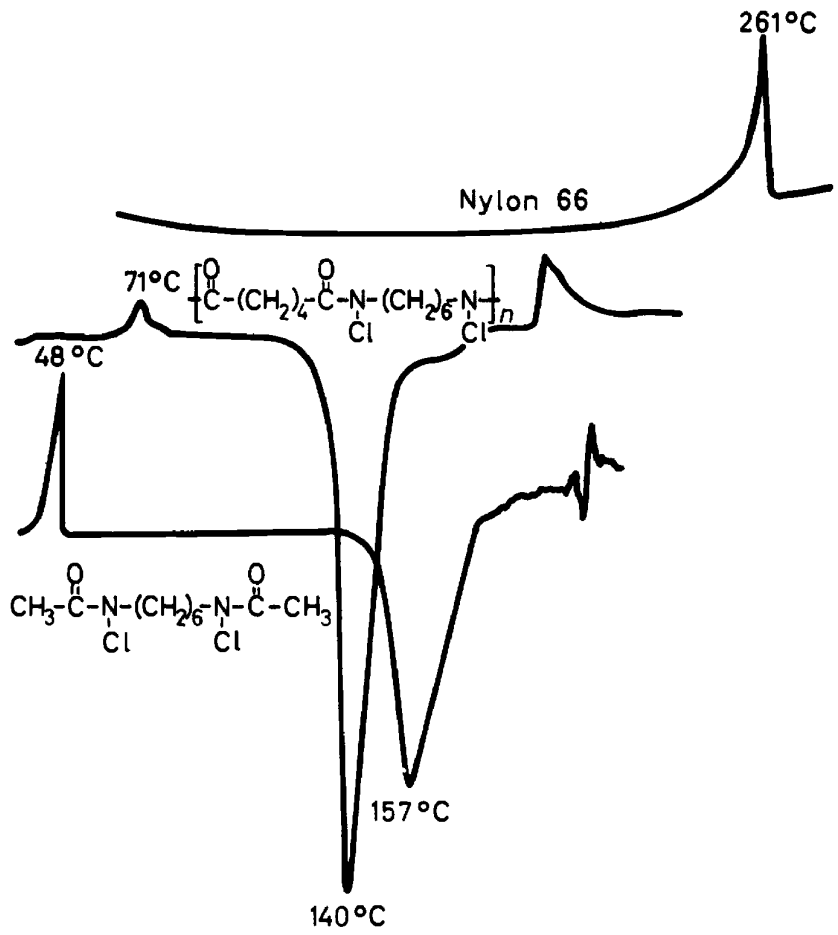

Figure 10. Thermograms of nylon 66 (XVII), $N$-chloro-nylon (XVIII) and chlorinated model compound $(\mathrm{XX})$. 
As we have no H-bonds in chlorinated products, the melting points are much lower than those for the amides. In the sample of nylon 66 we have been using here, we get an endothermal melting peak at $261^{\circ} \mathrm{C}$ (Figure 10) in the thermogram; after the chlorination the melting peak is at $71^{\circ} \mathrm{C}$. The chlorinated model compound melts at $48^{\circ} \mathrm{C}$. At $140^{\circ} \mathrm{C}$ and at $157^{\circ} \mathrm{C}$ there are great exothermal peaks. This transformation will be discussed further on page 263.

In order to determine $N$-chloro-amide groups quantitatively the polymer is treated with a potassium iodide solution and then the resulting iodine is titrated. The chlorine content of 30 per cent to nearly 100 per cent of theory depends on the chlorination agent and the experimental conditions. Some examples are to be seen in Table 9. During chlorination a chain degradation

Table 9. Chlorination of nylon $66(\bar{P} \sim 180)$.

\begin{tabular}{lrcr}
\hline $\begin{array}{c}\text { Chlorination } \\
\text { reagent }\end{array}$ & $\begin{array}{c}\text { Temp. } \\
{ }^{\circ} \mathbf{C}\end{array}$ & $\begin{array}{c}\text { Conversion } \\
\%\end{array}$ & $\bar{P}$ \\
\hline tert-BuOCl & -20 & $69-70$ & 137 \\
& +15 & $95-96$ & 118 \\
$\mathrm{KOCl}$ in $\mathrm{H}_{2} \mathrm{O}$ & 0 & $70-73$ & 132 \\
$\mathrm{Cl}_{2}+\mathrm{KHCO}_{3}$ & +15 & $80-89$ & 29 \\
$\mathrm{Cl}_{2} \mathrm{O}$ in $\mathrm{CCl}_{4}$ & -20 & $98-100$ & 34 \\
\hline
\end{tabular}

also takes place. The strongest degradation can be observed when chlorine or chloromonoxide are used. Tert-butylhypochlorite causes only a small reduction of the degree of polymerization and is therefore very suitable indeed. Naturally the polymers with the pendant amide- and imide-groups mentioned above (Scheme 4) are not decomposed during chlorination.

After having elucidated the structure of the chlorinated nylon we examined the chemical reactivity of the polymer as compared with the model compounds. We knew from former publications ${ }^{24}$ that $N$-chloroderivatives of cyclic and linear amides and imides react with diazomethane by inserting a methylene group; one gets $N$-chloromethyl derivatives (equation 12). This<smiles>[R]N([R])C[NH2+][CH-][NH2+]</smiles>

$\mathbf{R}: \mathrm{CH}_{3}-\underset{\text { II }}{\mathrm{C}-} ; \mathrm{C}_{6} \mathrm{H}_{5}-\underset{\|}{\mathrm{C}-}-p$-tosyl

$\mathrm{R}^{\prime}: \mathrm{CH}_{3}-; \mathrm{C}_{6} \mathrm{H}_{5}-\mathrm{CH}_{2}-$; cyclohexyl-; $i$-propyl-

reaction goes on under very mild conditions and with yields of 50 to 80 per cent, depending on the kind of substituent. All attempts to get this reaction also with $N$-chloro-nylon failed; we always got insoluble polymers, whose structures could not be defined. 
The reaction with potassium iodide shows that the $N$-chloro-polyamides are very good oxidizing agents. Therefore we tested whether they were also suitable for the oxidation of alcohol in analogy to $N$-bromosuccinimide.

If one dissolves $N$-chloro-nylon in benzene and adds the equivalent amount of pyridine and, say, cyclohexanol one observes that the content of the active chlorine decreases after a certain induction period. Finally a powder-like polymer precipitates which does not contain any chlorine and is nearly pure nylon. The solution contains more than 80 per cent of the theoretical amount of cyclohexanone (proved and determined by GPC). The reaction depends on the solvent. In DMSO no ketone is formed; in $\mathrm{CCl}_{4}$ or $\mathrm{CHCl}_{3}$ the reduced polymer precipitates as a gel and the separation of the oxidation products is difficult. We get an optimal reaction with benzene or cyclohexane, although the polymer is not soluble in cyclohexane. The oxidation then takes place in a heterogeneous medium. The possibility of separating the polymeric oxidation agent by filtration after the reaction is a great advantage. Thus many other secondary alcohols can be oxidized into ketones with nearly quantitative yields. The reaction can in general be described by equation 13 .

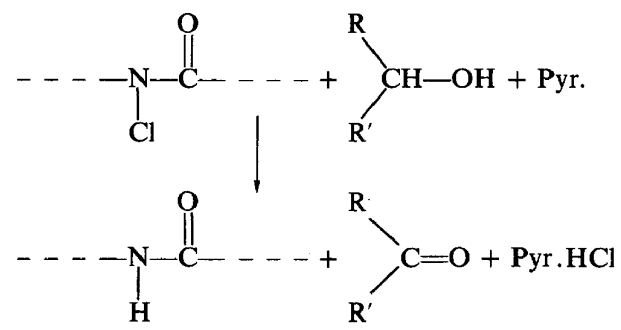

We chose some of the experiments described in the literature ${ }^{25,26}$ in order to make comparisons with the oxidation reaction of low-molecular $\mathrm{N}$ halogen amides. The results are listed in Table 10.

The yields determined by gas chromatography exceed 80 per cent when oxidized with $N$-chloro-nylon. The yields are also determined by the weights of semicarbazones and dinitrophenylhydrazones in order to compare the results with published data. We find that we get the same yields or in some cases even better ones with $\mathrm{N}$-chloro-nylon compared with $\mathrm{N}$-bromohydantoin or $N$-bromoacetamide.

Kinetic experiments on oxidation proved difficult because the reactions with $N$-chloro-nylon beyond a certain stage proceed in a heterogeneous medium $^{27}$. It was clearly shown, however, that the active chlorine of the polymer is consumed faster than in model compounds and $N$-chlorocaprolactam.

Primary alcohols can also be oxidized with $N$-chloro-nylon. At $35^{\circ} \mathrm{C}$ benzylalcohol is transformed into benzaldehyde after 24 hours with a yield of 95 per cent. The aldehydes formed are not oxidized even with a great excess of $N$-chloro-nylon. The oxidation of aliphatic primary alcohols yields the esters of the corresponding acids. We can assume that in this case semiacetals as intermediates are formed in a similar manner to the oxidation with 
Table 10. Oxidation of secondary alcohols with $N$-chloro-nylon $(N \mathrm{Cnyl})$. $N$-bromo-hydantoin $(N \mathrm{BH})$ and $N$-bromo-acetamide $(N \mathrm{BA})$; temp. $35^{\circ} \mathrm{C}$; solvent: benzene; time : $24 \mathrm{~h}$.

\begin{tabular}{|c|c|c|c|c|}
\hline \multirow{3}{*}{ Alcohd1 } & \multicolumn{4}{|c|}{ Yields of ketones with } \\
\hline & \multicolumn{2}{|c|}{ NCnyl } & \multirow{2}{*}{$\begin{array}{l}\text { NBH } \\
\% \\
\text { (b) }\end{array}$} & \multirow{2}{*}{$\begin{array}{l}N B A \\
\% \\
(\mathrm{c})\end{array}$} \\
\hline & $\begin{array}{l}\% \\
\text { (a) }\end{array}$ & $\begin{array}{r}\% \\
\text { (b) }\end{array}$ & & \\
\hline Cyclohexanol & 82 & - & - & 45 \\
\hline $\mathrm{Ph}-\mathrm{CH}_{2}-\mathrm{CH}-\mathrm{CH}_{3}$ & 90 & 62 & 51 & 35 \\
\hline $\mathrm{Ph}-\left(\mathrm{CH}_{2}\right)_{2}-\stackrel{\mathrm{OH}}{\mathrm{CH}}-\mathrm{CH}_{3}$ & 95 & 68 & 74 & - \\
\hline$\left(\mathrm{Ph}-\mathrm{CH}_{2}\right)_{2}-\underset{\mathrm{OH}}{\mathrm{OH}}$ & 62 & - & 一 & $<1$ \\
\hline $\mathrm{Ph}-\mathrm{CH}_{2}-\underset{\mathrm{OH}}{\mathrm{CH}-i \text {-prop. }}$ & 92 & 60 & 53 & $<1$ \\
\hline
\end{tabular}

(a) with GPC.

(b) semicarbazone.

(c) 2,4-dinitrophenylhydrazone.

chromic acid ${ }^{28}$. Actually, an equimolar mixture of octanol and octanal with $N$-chloro-nylon forms 70 per cent $n$-octyl-caprylate after a few hours. The oxidation of pure octanol proceeds much more slowly.

As mentioned above a strongly exothermal transformation takes place at $140^{\circ} \mathrm{C}$. Without any solvent highly chlorinated nylon can decompose in an explosive way. We suppose that this transformation is an analogous reaction to the Hofmann-Löffler rearrangement of $N$-halogen amines ${ }^{29}$. It proceeds by a radical mechanism and leads to chain-halogenated $N$-alkyl amines. These rearrangements have also been described with $\mathrm{N}$-bromo- and $N$-chloro-carboxamides (equation 14). They lead partly to the $\gamma$-chloro-<smiles>[R]CCCC(=O)N([R])Cl</smiles>

$$
\mathbf{R}^{\prime}: \text { alkyl } ; \mathbf{R}: t-\mathrm{C}_{4} \mathrm{H}_{9}
$$

carboxamides $^{30}$ with satisfactory yields; usually a cyclization reaction follows in the case of $N$-bromo compounds. If we proceed with the rearrangement of the $N$-chloro-nylon under comparatively mild conditions we actually get a product which contains approximately the same amount of total chlorine but no active chlorine linked to nitrogen. The position of the chlorine and the structure of the polymer are still under investigation ${ }^{31}$.

Further, it is known that this rearrangement is also induced by light, 


\section{ROLF C. SCHULZ}

although $N$-chloro-carboxamide above $250 \mathrm{~m} \mu$ has no absorption maximum $^{32}$. The mechanism of this reaction is still obscure. Nevertheless we have also tried to make this photo-rearrangement with $N$-chloro-nylon. If we cast a thin film of this polymer on plates of rocksalt and record the i.r. spectrum we get the spectrum already mentioned above (Figure 8 , solid line). Even a longer i.r. irradiation does not cause any changes. Upon irradiation of the film with a mercury vapour lamp $(365 \mathrm{~nm})$ for some seconds the NH-bands appear in the spectrum at 3300 and $3030 \mathrm{~cm}^{-1}$ (Figure 11). This

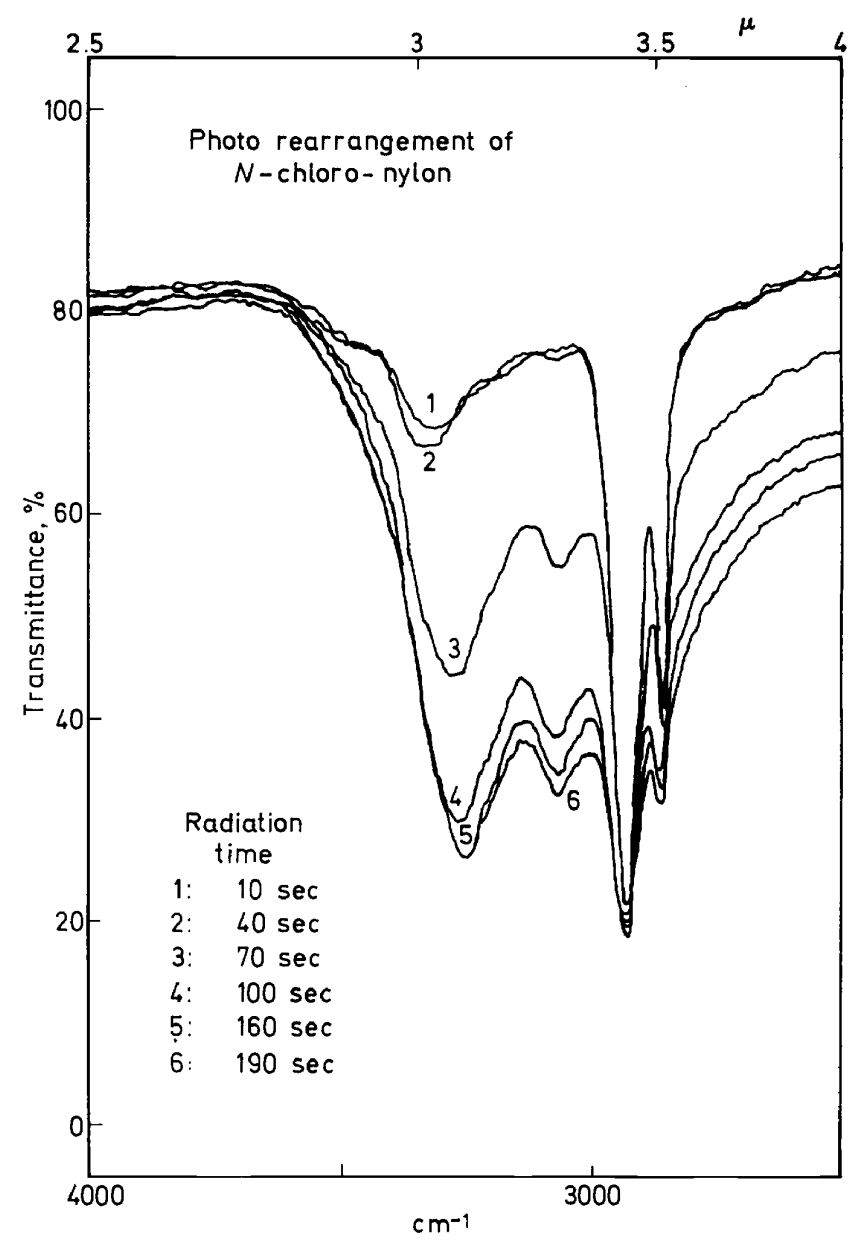

Figure 11. Change of i.r. spectra of chlorinated nylon during irradiation with a mercury lamp.

means that the rearrangement proceeds also in a solid state. After about five minutes of radiation we get an i.r. spectrum similar to that of the original nylon. With increase of the NH-bands the ability to oxidize disappears; in fact irradiated $N$-chloro-nylon does not actually form any iodine from potassium iodide solution. 


\section{THE COMPARISON OF ANALOGOUS REACTIONS OF MACROMOLECULES}

We gratefully acknowledge the financial support of 'Deutsche Forschungsgemeinschaft'. H. Schuttenberg expresses his sincere gratitude for an 'Alexander von Humboldt-Stipendium' and R. H. Jung is grateful for a 'Liebig-Stipendium' from the 'Fonds der Chemischen Industrie'.

\section{REFERENCES}

1 E. M. Fettes (Ed.) Chemical Reactions of Polymers High Polymer Series, Vol. XIX, Interscience: New York (1964).

Houben-Weyl, Methoden der Organischen Chemie E. Müller (Ed.) 4th ed., Vol. XIV/2, p 637. Thieme: Stuttgart (1963).

IUPAC Symposium, Brussels-Louvain, Belgium (June 1967); Pure Appl. Chem. 16, Nos. 2-3 (1968).

International Conference on Chemical Transformations of Polymers, Bratislava (June 1968), Europ. Polym. J. Suppl. (August 1969).

2 R. B. Merrifield, J. Amer. Chem. Soc. 85, 2149 (1963); 86, 304 (1964);

R. L. Letsinger and V. Mahadevan, J. Amer. Chem. Soc. 87, 3526 (1965);

F. Cramer, R. Helbig, H. Hettler, H. Scheit and H. Seliger, Angew. Chem. 78, 640 (1966).

3 C. G. Overberger, J. C. Salamone, J. Cho and H. Maki, Ann. N.Y. Acad. Sci. 155, 431 (1969). G. Manecke, Natur wissenschaften, 51, 25 (1964).

G. Manecke and G. Günzel, Naturwissenschaften 54, 531 (1967).

A. S. Lindsey, J. Macromol. Sci., Rev. Macromol. Chem. C3, 1 (1969).

4 R. E. Moser and H. G. Cassidy, J. Polym. Sci. B2, 545 (1964).

R. Searle, J. L. R. Williams, J. C. Doty, D. E. DeMeyer, S. R. Merrill and T. M. Laakso, Makromol. Chem. 107, 246 (1967).

C. David, W. Demarteau and G. Geuskens, Europ. Polym. J. 6, 537 (1970).

D. Bellus et al. J. Polymer. Sci. A-1, 9, 69 (1971).

5 R. C. Schulz and R. H. Jung, Makromol. Chem. 96, 295 (1966); 116, 190 (1968); R. C. Schulz and R. H. Jung, Angew. Chem. 79, 422 (1967); Angew. Chem. Internat. Ed. 6461 (1967).

6 E. L. Eliel, Stereochemistry of Carbon Compounds, McGraw-Hill: New York (1962).

K. Mislow, Introduction to Stereochemistry, Benjamin: New York (1965).

7 R. C. Schulz, IUPAC Symposium, Budapest (1969). Main Lectures, pp. 185-212.

8 Some other polymers with atropisomer base units were described by C. G. Overberger et al. IUPAC Symposium, Tokyo (1966), Preprint 2.3.02 J. Polym. Sci. A-1, 8, 2275 (1970).

9 F. Bell, J. Chem. Soc. 835 (1934).

10 R. H. Jung, unpublished results.

11 R. C. Schulz and R. H. Jung, Tetrahedron Letters, 4333 (1967).

12 A. Braun, H. G. Cassidy, R. C. Schulz and H. Tanaka, Makromol. Chem. 146, 195 (1971).

13 W. Slough, Trans. Faraday Soc. 58, 2360 (1962);

G. Smets, V. Balogh and Y. Castille, J. Polym. Sci. C4, 1467 (1964);

R. Knoesel, Bull. Soc. Chim. France, 4299 (1967);

W. Klöpffer and W. Willicks, Makromol. Chem. 115, 156 (1968)

14 T. Sulzberg and R. J. Cotter, Macromolecules, 1, 554 (1968).

15 N. C. Yang and Y. Gaoni, J. Amer. Chem. Soc. 86, 5022 (1964).

16 G. Briegleb, Elektronen-Donator-Acceptor-Komplexe, Springer: Berlin (1961);

R. Foster, Organic Charge-Transfer Complexes, Academic Press: London (1969).

17 H. Tanaka, Mainz and Darmstadt (1970), unpublished results.

18 W. Liptay, Z. Elektrochem. 65, 375 (1961).

19 J. Parrod, P. Rempp and R. Knoesel, J. Polym. Sci. C16, 4049 (1965).

20 H. Schuttenberg and R. C. Schulz, Makromol. Chem. 143, 153 (1971)

21 H. Schuttenberg and R. C. Schulz, Angew. Makromol. Chem. 18, 175 (1971).

22 M. Okawara and H. Shinohara, J. Chem. Soc. Japan, Industr. Chem. Sect. 60. 75 (1957): Chem. Abstr. 53, 5730h US Pat. No. 2853475 ;

W. A. Murphey, Chem. Abstr. 53, 3725h

23 R. C. Schulz, Pure Appl. Chem. 16, 433 (1968). Angew. Makromol. Chem. 4/5, 1 (1968).

24 R. A. Corral and O. O. Orazi, Tetrahedron Letters 1693 (1964);

O. O. Orazi, R. A. Corral and H. Schuttenberg, Tetrahedron Letters, 2639 (1969). 
25 R. A. Corral and O. O. Orazi, Anal. Asoc. Quim. Argentina, 55, 205 (1967); Chem. Abstr. 69, $105572 \mathrm{r}$

26 J. Lecomte and H. Gault, C.R. Acad. Sci., Paris 238, 2538 (1954);

J. Lecomte and C. Dufour, C.R. Acad. Sci., Paris 234, 1887 (1952).

${ }^{27}$ K. Hahn, Darmstadt (1971), unpublished results.

28 W. A. Mosher and D. M. Preis, J. Amer. Chem. Soc. 75, 5605 (1953).

29 R. S. Neale, Synthesis, 1,1 (1971).

30 R. S. Neale, N. L. Marcus and R. G. Schepers, J. Amer. Chem. Soc. 88, 3051 (1966).

31 M. Müller, Darmstadt (1971), unpublished results.

32 R. S. Neale and M. R. Walsh, J. Amer. Chem. Soc. 87, 1255 (1965); A. L. J. Beckwith and J. E. Goodrich, Austral. J. Chem. 18, 747 (1965). 